\title{
Acceptability Scores and Enhancement of Nutritional Quality Parameters of Buttermilk Enriched with Pomegranate Peel Powder
}

\author{
Mumtaz Begum, Zebish Ali and Ritu Toijam* \\ Sam Higginbottom University of Agriculture, Technology and Sciences, H.P, India \\ *Corresponding author
}

\section{A B S T R A C T}

\begin{tabular}{|l|}
\hline Ke y w or d s \\
Pomegranate peel \\
powder, Buttermilk, Low \\
fat curd
\end{tabular}

Fit and fine health is an asset in modern world. A diet sufficient in quantity as well as quality is required for a good health. Macro and micronutrient deficiencies, inadequate nutritional awareness affect the lives of western nation less dramatically than those are the citizen of developing countries. The grave situation by overpopulation and underproduction of food on international level is well documented. Therefore, the present study was undertaken to overcome the ill effects of nutrition related problems with improving the quality of life by the judicious use of pomegranate peel powder in conventional preparation. The main aim of the study was to develop value added product like buttermilk with the incorporation of dehydrated pomegranate peel powder at different levels. The results of sensory appraisal revealed that among different proportion of ingredients used with the combination of $90 \%$ low fat curd $10 \%$ of pomegranate peel powder was most acceptable and received the highest ratings.

\section{Introduction}

Pomegranate peel is rich in antioxidants and these antioxidants are highly capable for protecting Low Density Lipoprotein cholesterol against oxidation and lower the risk of cancer and heart disease (Hossin, 2009). It has wound healing properties anticarcinogenic, anti-inflammatory and immune modulating activity (Jurenka, 2008). Polyphenols are the antioxidant components, and they help to protect cells from damage and may lower inflammation in the body (Kanatt and Chander, 2010). Phenolic content present in pomegranate peel are Ellagic acid, Catechins, Gallic acid, Resocenol, Protocatechol, Parahydroxy benzoic acid, phenol (Rowayshed et al., 2013). Peel is rich source of rough dietary fibers known as NSP (non-soluble polysaccharides) such as hemicellulose, pectin, tannins, gum etc (Zhenbin et al., 2011) these compounds add bulkiness to the food and help prevent constipation. It further binds to bile salts (produced from cholesterol) and eliminate them from gut, thus lower serum LDL cholesterol levels (Neyrinck et al., 2013). Pomegranate peel acts as a prebiotic and encourages the growth of human gut microflora and beneficial probiotic bacteria in the intestines (Bialonska et al., 2009).

In this study, dehydrated pomegranate peel powder was used. It was used as an ingredient 
in conventional recipe and increases quality and nutritive value of the product. It is also an excellent source of iron, calcium, Fiber, protein, vitamin $\mathrm{C}$ and also minor constituents- polyphenols, flavonoids and many minerals. Study involves the preparation of buttermilk with the incorporation of pomegranate peel powder in different concentrations. It provides healthy and nutritious snacks to protect from various ailments.

\section{Materials and Methods}

In present study, pomegranate peel powder was used and was collected from juice shop of Allahabad.

Buttermilk was prepared with different proportions of pomegranate peel powder $(5 \%$, $10 \%$ and $15 \%)$. Standard recipe was made with low fat curd (Fig. 1). Sensory evaluation was conducted to evaluate the acceptability of all different proportions of the recipes on the basis of the 9 point hedonic scale by 25 semitrained panel members to get the most acceptable level from these recipes. Proximate analysis of nutrients of the most acceptable form of recipe i.e. protein, fat, fibre, carbohydrate, calcium and iron content was done by using standard procedures (AOAC). Data obtained were subjected to the analysis of Mean, Standard deviation (Table 1).

\section{Results and Discussion}

The results obtained from the present investigation are presented below:

\section{Sensory evaluation}

The average results of sensory evaluation of different proportions of buttermilk are listed in table 2. According to the results $\mathrm{A}_{2}$ sample (90\% LFC and 10\% PPP) showed the highest overall acceptability scores. As the level of pomegranate peel powder increased, the sensory scores for different attributes decreased in all samples of buttermilk. Fathima and Puraikalen (2013) observed that the flavor and taste of the pomegranate peel incorporated idli at $10 \%$ level was obtained higher scores as comparable with the idli prepared from idli flour only.

\section{Table.1 Percent incorporation of dehydrated pomegranate peel powder in} Buttermilk with basic ingredients

Sample of buttermilk Different proportions of pomegranate peel powder (PPP) and low fat curd (LFC) Std. of buttermillk= SB $100 \%$ LFC

\begin{tabular}{|c|}
\hline Test sample of buttermilk \\
\hline $\mathbf{A}_{1}$ \\
\hline $\mathbf{A}_{2}$ \\
\hline $\mathbf{A}_{3}$ \\
\hline
\end{tabular}

Buttermilk

$5 \% \mathrm{PPP}+95 \%$ LFC

$10 \% \mathrm{PPP}+90 \% \mathrm{LFC}$

$15 \% \mathrm{PPP}+85 \% \mathrm{LFC}$

\begin{tabular}{|c|c|c|c|c|}
\hline & $\begin{array}{l}\text { Colour and } \\
\text { appearance }\end{array}$ & $\begin{array}{c}\text { Body and } \\
\text { Texture }\end{array}$ & $\begin{array}{l}\text { Taste and } \\
\text { Flavour }\end{array}$ & Overall acceptability \\
\hline SB & 6.6 & 6.6 & 7.6 & 6.9 \\
\hline$A_{1}$ & 7.3 & 6.6 & 8.4 & 7.4 \\
\hline $\mathbf{A}_{2}$ & 7.6 & 7.6 & 8.8 & 8 \\
\hline $\mathbf{A}_{3}$ & 6.9 & 7.3 & 6.3 & 7 \\
\hline
\end{tabular}


Table.3 Nutritional analysis of Buttermilk prepared by incorporation of low fat curd and dehydrated Pomegranate peel powder

\begin{tabular}{|l|c|c|}
\hline Nutrient content of sample of Buttermilk & SB & $\mathbf{A}_{\mathbf{2}}$ \\
\hline Protein (g) \% & 10.1 & 10.9 \\
\hline Carbohydrate (g)\% & 109 & 102.1 \\
\hline Fibre (g)\% & 5.8 & 7.9 \\
\hline Iron (mg)\% & 2.6 & 3.8 \\
\hline Calcium (mg)\% & 119.1 & 257 \\
\hline
\end{tabular}

Fig.1 Flow chart for the preparation of pomegranate peel powder

Collection of pomegranate peel

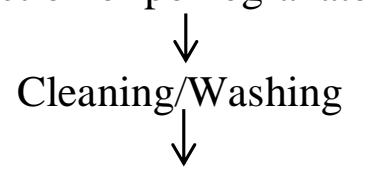

Cut into pieces

Spreading on flat wooden trays

Drying at $50^{\circ}-60{ }^{\circ} \mathrm{C}(6-7 \mathrm{hrs}$ in hot air oven $)$

Dehydration till moisture becomes $6-8 \%$

Grinding into flour, sieved

Packed and stored the dehydrated powder

Fig.2 Nutrient analysis of Buttermilk

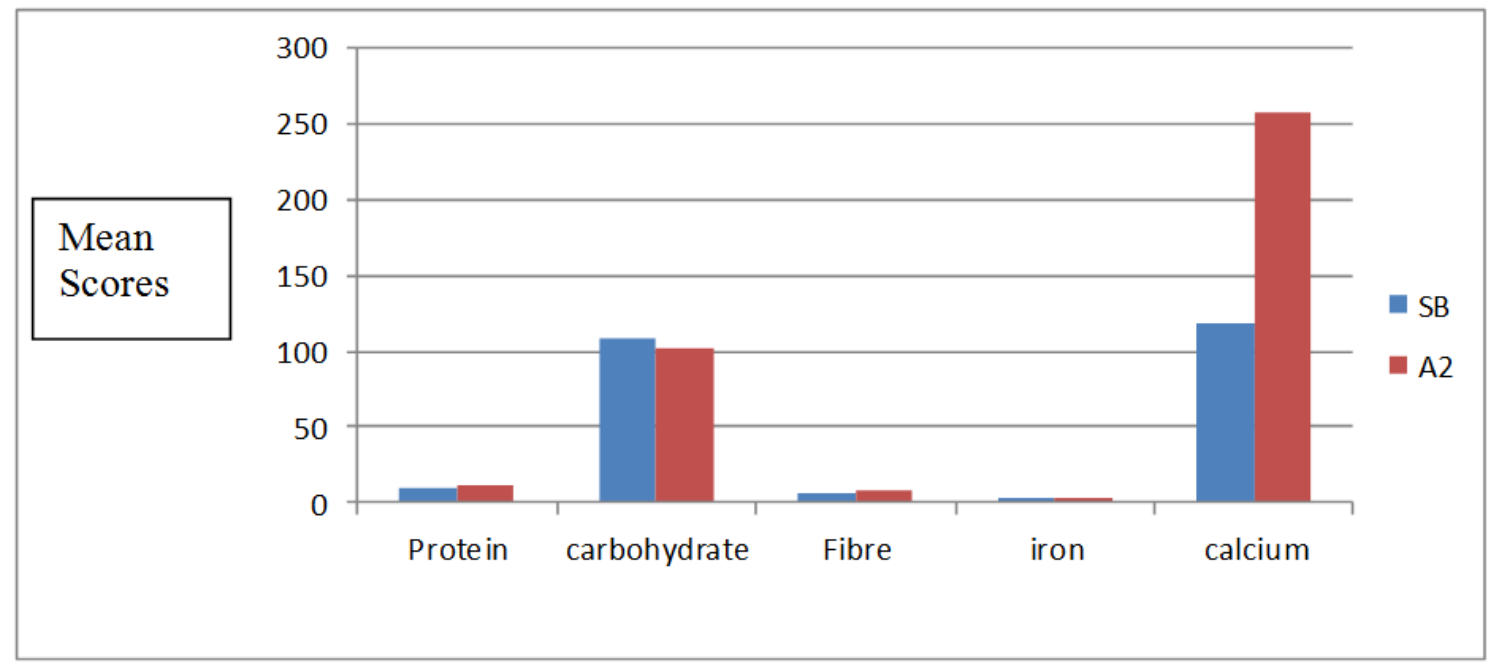




\section{Quality parameters}

Nutrient analysis (Table 3) was done with the most acceptable sample of buttermilk which had received the highest scores in terms of all attributes and overall acceptability. In that sample of buttermilk, the proportion of ingredients was 90:10 for low fat curd and pomegranate peel powder respectively. The values of protein, fibre, calcium and iron in that sample of buttermilk were $10.9 \mathrm{~g} / 100 \mathrm{~g}$, $7.9 \mathrm{~g} / 100 \mathrm{~g}, 257 \mathrm{mg} / 100 \mathrm{~g}$ and $3.8 \mathrm{mg} / 100 \mathrm{~g}$, respectively. Incorporation of pomegranate peel powder in small quantity will improve the protein, iron, calcium and fibre without causing significant difference in the acceptability of the developed product. Results revealed that buttermilk fortified with $10 \%$ pomegranate peel powder showed the possibility of incorporation to be used on commercial level. Results obtained are depicted in Table 3 and figure 2.

Value added product namely, buttermilk was formulated using low fat curd and pomegranate peel powder in proportions of $95 \%, 90 \%$ and $85 \%$ and $5 \%, 10 \%$ and $15 \%$ levels, respectively. Product developed with 90\% low fat curd and 10\% pomegranate peel powder received highest acceptability scores when evaluated by a panel of judges on the basis of 9 point hedonic scale.

All the sensory attributes were analysed in fresh sample. Most acceptable proportions of buttermilk were analysed for their nutritional composition viz., Protein, fibre, carbohydrates, iron and calcium. Nutrient content of the product increased at all the levels of incorporation. Thus, it can be concluded from the present study, that pomegranate peel powder incorporated with value added buttermilk can be a good source of fiber, protein, calcium and iron product like these are beneficial for people of health degenerative diseases as being a good source of prebiotics and probiotics and to combat nutritional deficiencies with improving quality of life.

\section{References}

A.O.A.C. (2005) "Official method of analysis of the association of official analytical chemists". $18^{\text {th }} \mathrm{Ed}$.

Bialonska, D., S.H. Kasimsetty, K.K. Schrader, D. Ferreira (2009) "The effect of pomegranate (Punica granatum L.) Byproducts and ellagitannins on the growth of human gut bacteria". Journal of Agricultural Food Chemistry, 57(61) pp. 8344-8349.

Fathima, S., Puraikalan Y.D., (2013) "Development of Food Products Using Pomegranate Skin.” International Journal of Science and Research Vol. 4(3) pp. 1756- 1758.

Hossin. L.A., (2009) "Effect of pomegranate peel and its extracts on obese Hypercholesterolemic rats" Pakistan journal of nutrition 8(8): 1251-1257

Jurenka, J. (2008) "Therapeutic Applications of Pomegranate (Punica granatum L.) peel" Alternative Medicine Review. Vol. 13(2):128-144.

Kanatt, S.R., Chander, A., (2010). "Antioxidant and antimicrobial activity of pomegranate peel extract improve shelf life of chicken products". International Journal of Food Science and Technology, 45, pp. 216-222.

Neyrinck A.M., Van Hée V.F., Bindels L.B., Backer, F., Cani. P.D., Delzenne N.M., (2013) "Polyphenol-rich extract of pomegranate peel alleviates tissue inflammation and hyper cholesterolaemia in high-fat dietinduced obese mice" British Journal of Nutrition, 7 pp. 802-809. 
Rowayshed, G., Salama, A., Abul-Fadl, M., Akila-Hamza, S. and Emad, A. Mohamed (2013) "Nutritional and Chemical Evaluation for Pomegranate (Punica granatum L.) Fruit Peel and Seeds Powders By Products.” Middle
East Journal of Applied Sciences Vol. 3(4) pp. 169-179.

Zhenbin W., Zhongli P., Haile M. and Griffiths G. A., (2011) "Extract of Phenolics from Pomegranate Peels". The Open Food Science Journal Vol.5, $\operatorname{Pg} 17-25$

\section{How to cite this article:}

Mumtaz Begum, Zebish Ali and Ritu Toijam. 2018. Acceptability Scores and Enhancement of Nutritional Quality Parameters of Buttermilk Enriched with Pomegranate Peel Powder. Int.J.Curr.Microbiol.App.Sci. 7(12): 3271-3275. doi: https://doi.org/10.20546/ijcmas.2018.712.378 